\title{
Large/Massive Tears, Fatty Infiltration, and Rotator Cuff Muscle Atrophy: A Review Article With Management Options Specific to These Types of Cuff Deficiencies
}

\author{
Gandhi Nathan Solayar, ${ }^{1,2}$ Bradley Seeto, ${ }^{1,2}$ Darren Chen, ${ }^{1,2}$ and Samuel Mac Dessi ${ }^{1,2}$ \\ ${ }^{1}$ Sydney Knee Specialists, NSW 2217, Sydney, Australia \\ ${ }^{2}$ St George's Private Hospital, Kogarah NSW 2217, Sydney, Australia \\ *Corresponding author: Gandhi Nathan Solayar, Sydney Knee Specialists, NSW 2217, Sydney, Australia. Tel: +61-434862511, E-mail: solayarg@hotmail.com
}

Received 2015 November 19; Revised 2015 December 22; Accepted 2016 January 2.

\begin{abstract}
Context: There are many studies in the literature looking into factors affecting outcomes in rotator cuff surgery. The aetiology of rotator cuff deficiency is often multi-factorial and there are many facets towards successful management in this often debilitating condition.

Evidence Acquisition: We performed a literature search of MEDLINE and Embase databases using the terms large rotator cuff tears, fatty infiltration rotator cuff, rotator cuff atrophy, rotator cuff augmentation, rotator cuff tendon transfers, allografts rotator cuff repair, xenograft rotator cuff repair and synthetic grafts rotator cuff repair.

Results: In this article, we focus particularly on the aetiology, pathology and prognosis of large tears, fatty infiltration and muscle atrophy of the rotator cuff. An overview of the various treatment strategies and current/future concepts are also discussed in managing patients with these types of rotator cuff deficiencies.

Conclusions: Large tears, fatty infiltration and muscle atrophy of the cuff are challenging. An in-depth understanding of these elements may prove vital for the practising orthopedician in determining the right course of management. Techniques in strengthening the repair construct using augmentation play an important role in the treatment of this condition.
\end{abstract}

Keywords: Rotator Cuff, Large Tears, Massive Tears

\section{Context}

Surgical repair of rotator cuff tears (RCT) is widely recognised as the preferred management option. It often results in an improved functional outcome and a reduction of pain symptoms. Reported success following rotator cuff repair (RCR) range between 38\% to 95\% (1-6). Current literature reports a multitude of studies looking at variables which may impact surgical outcomes. These include but are not limited to: age, gender, partial versus fullthickness tears, types of repair (single vs. double row), comorbidities, open versus arthroscopic, implant types, tear characteristics (e.g. crescent, L- shaped), post-operative rehabilitation, surgeons experience etc. In particular, the extent of the tear (large, massive) and muscle quality (fatty infiltration, atrophy) have been implicated as predictors of outcome. In this review article, we focus on the latter aforementioned variables from appropriate diagnosis to proper management including potential pitfalls.

\section{Evidence Acquisition}

The authors performed a review of the current literature on rotator cuff repair on large tear, fatty infiltration and muscle atrophy of the rotator cuff. Particular focus was on obtaining current literature pertaining treatment strategies including cuff repair techniques, tendon transfers, rotator cuff augmentation, allografts, xenografts and synthetic grafts. The literature search was performed on articles indexed on MEDLINE and Embase databases. Over 400 articles were obtained and of those, 76 articles were extensively reviewed and used as reference for this article.

\section{Results}

\subsection{Large/Massive Rotator CuffTears}

The prevalence of rotator cuff tears is high. They range from $8 \%$ to $49.4 \%$ encompassing both partial and fullthickness tears based on cadaveric and radiological studies (7-9). The aetiology of these tears vary from trauma, genetic predisposition, scapular morphology and degenerative tendonopathy $(10,11)$. Degenerative changes that manifest at the histological level include features of hypoxic degenerative tendonopathy, mucoid degeneration, tendolipomatosis and calcifying tendonopathy, either individually or in combination (12). Matthews et al. ob-

Copyright (C) 2016, Iran University of Medical Sciences. This is an open-access article distributed under the terms of the Creative Commons Attribution-NonCommercial 4.0 International License (http://creativecommons.org/licenses/by-nc/4.0/) which permits copy and redistribute the material just in noncommercial usages, provided the original work is properly cited. 
served that smaller RCT showed higher degrees of cellularity and intimal hyperplasia with increased expression of leucocyte and vascular markers. Reparative changes were inversely proportional to the size of RCT (13).

Large RCTs are defined as cuff defects measuring from 3 to $5 \mathrm{~cm}$ in two or more planes while massive tears are defined as RCTs greater than $5 \mathrm{~cm}$ (14). These present a problem for the operating surgeon as difficulties arise with regards to adequate footprint coverage, tendon mobilisation, post-operative repair quality and the risk of re-tear. Recognising a large or massive tear pre-operatively has important implications in planning as well as in counselling patients regarding their post-operative outcomes.

Ultrasound and magnetic resonant imaging (MRI) are common modalities in diagnosing RCTs. A recent Cochrane review showed that these two imaging methods have good diagnostic accuracy in detecting full-thickness tears (15). Other options include arthrography, computer tomography arthrography and magnetic resonant arthrography (MRA) which are more invasive. MRA has been shown to have better accuracy in detecting tear sizes compared to conventional MRI. Notably, it allows for better assessment of the extent of the tear in both sagittal and coronal planes with improved morphological classification (16). Furthermore, it has been shown that MRI has the potential of recognising predictors for reparability; in particular, tendon retraction to or beyond the glenoid, increased inferior glenohumeral distance and a positive tangent sign which may preclude a successful outcome surgical repair of large/massive RCTs (17).

\subsection{Fatty Infiltration and Muscle Atrophy}

Rotator cuff muscle quality indicators such as fatty infiltration and atrophy have been implicated as predictors of outcome following surgical repair. It has been suggested that a full-thickness RCT causes tendon and muscle belly retraction which results in changes in the pennation angle between muscle fibres and subsequent development of fatty infiltration (18). Goutallier and Bernageau were the first to report a classification system to determine the extent of fatty infiltration within the rotator cuff musculature based on computed tomography (CT) imaging (19). A similar classification system was developed by Fuchs et al. this time employing MRI (T1 sequences) which compared the ratio of fat to muscle on the oblique sagittal images (20). Stages $0-1$ is considered normal with no trace being stage 0 and trace amounts of fat within the muscle bellies being stage 1 . Pathologic states are stages 2 - 4: higher muscle to fat ratio (2); equal muscle to fat ratio (3); and more fat than muscle (4). Other methods to identify supraspinatus muscle atrophy include the scapula ratio and the "tangent sign". The scapula ratio is the percentage of the cross-sectional area of the supraspinatus muscle to the area of the supraspinatus as measured on the sagittal oblique MRI plane. If this ratio is less than $50 \%$, supraspinatus muscle atrophy is indicated (21). The tangent sign method also employs similar MR imaging planes and bony landmarks. Normal supraspinatus muscle should cross superior to a line drawn through the superior borders of the scapular spine and the superior margin of the coracoid process. This finding is not present with atrophy (22).

Influence of aging on fatty infiltration is still being evaluated. It was initially thought that fatty degeneration is not related to aging and only occurs in the presence of a tear $(23,24)$. More recent evidence suggests that age relates to the severity of RCTs and therefore, the severity of fatty infiltration and atrophy (25). Fatty infiltration is progressive and irreversible in untreated cases $(25,26)$. Fatty changes begin from tear onset which maybe earlier than symptoms and progresses faster in patients with more than one tear (27). On average, stage 2 changes takes around 3 - 4 years from onset of symptoms and stage 3 - 4 takes around 6 years (25).

It is well known that the worse the amount of muscle degeneration, the higher the failure rates following rotator cuff repair (28-30). Initial reports of improvements in rotator cuff atrophy following repair by Thomazeau et al. have been challenged in more recent studies by Gladstone et al. which found that rotator cuff repair did not positively alter fatty infiltration nor atrophy $(30,31)$. Gladstone et al. further showed that re-tears were higher in the setting of supraspinatus atrophy. They reported over $67 \%$ re-tears in the setting grade 2 atrophy or greater (31). Infraspinatus degeneration has also been shown to significantly co-relate with inferior outcomes. This may relate to the fact that tears extending to involve the infraspinatus are much larger. An ineffective infraspinatus may offset normal glenohumeral biomechanics through alterations in anterior-posterior force-coupling thus resulting in poorer outcomes even after successful rotator cuff repairs $(27,32)$. It is imperative therefore that rotator cuff repairs be undertaken prior to the development of atrophy/fatty infiltration which may improve healing rates and thus, functional outcomes $(25,26,31)$.

\subsection{Management Options}

Management of massive tears and degenerative rotator cuff continues to evolve. Options include conservative debridement, tendon-to-bone repair, tendon transfers and allograft reconstruction.

\subsubsection{Debridement and Sub-Acromial Decompression}

Debridement involves excision of loose/unstable tissue of the cuff remnant either arthroscopically or via an open approach coupled with a sub-acromial decompression. Ellman et al. looked at the long term followup of their cohort over $2-7$ years. They found that in patients with massive cuff tears, debridement alone provided significant pain relief but had no effect on improving function and range of motion (33). A study 
by Scheibel et al. reported similar results following subacromial decompression for large and irreparable tears showing improvement of pain symptoms while preserving the coraco-humeral ligament thus maintaining the integrity of the coraco-humeral arch (34). Levy et al. and Zvijac et al. in their series found that while debridement improved pain scores in the short term (mean 24.6 months), patients with massive tears showed deterioration of their overall pain and functional outcomes at 3 - 6 years $(35,36)$. Overall, results of debridement alone appears inferior to rotator cuff repair (37-39).

\subsubsection{Surgical Repair of Large/Massive Rotator Cuff Tears}

Biomechanical goals for rotator cuff repair involves high fixation strength while reducing gap formation thereby allowing maximal stability till healing occurs between the tendon-to-bone interface (40). Studies have shown that double-row (DR) fixation shows a higher load to failure compared to single-row (SR) techniques thereby potentially reducing pull-out failure (41-43). However, clinical outcomes when dealing with small to medium RCT show similar results between both DR and SR techniques (44-46). A study by Park et al. while supporting the use of SR for small to medium sized tears, showed superior results with $\mathrm{DR}$ techniques when dealing with large to massive RCTs (47).

The crucial problem in achieving adequate DR fixation involves availability of tendon length and excursion. The large/massive tear characteristics (crescent, U, L-shaped or in combination) requires different approaches to surgical management. Management of U-shaped tears are particularly challenging. The lack of medial-to-lateral mobility often precludes direct footprint repair. Studies by Burkhart et al. have shown that in certain U-shaped tears, there appears to be an increased anterior-to-posterior mobility than previously thought. Side-to-side suturing from medial to lateral, of the anterior and posterior leaves results in convergence of the free end towards the bone bed of the humerus. The free margin is then repaired on to the cuff footprint with minimal strain across the tendon; the appropriately named 'margin convergence' technique $(48,49)$. L-shaped tears are approached in a similar manner with side-to-side sutures of the longitudinal split and tendon-to-bone repair of the free margins. Care must be taken to identify the more mobile of the L-shaped tear 'corner' to allow for restoration (50).

In cases where there is still severe medial-to-lateral excursion, a novel way of overcoming this is via interval slides, first described by Tauro and further expounded by Lo and Burkhart. The anterior slide releases the interval between supraspinatus and rotator interval thereby sacrificing the posterior portion of the coraco-humeral ligament. The posterior slide involves releasing the interval between supraspinatus and infraspinatus tendons. Excursion increases of $1-2 \mathrm{~cm}$ can be expected following an anterior interval slide while combined anterior and posterior slides can achieve excursions up to $3-4 \mathrm{~cm}$ (50, 51). Caution is indicated when choosing a posterior slide as there is evidence that such repairs are not significantly better when compared to partial repairs without the addition of interval slides (52).

The appropriate approach when considering arthroscopic versus open techniques are still debatable. The literature shows equivocal results in terms of a favoured approach with the main pre-determining factor being the extent and characteristic of the RCT (53-55). There are however potential benefits of an arthroscopic approach over open repairs as this techniques allows for full visualisation of the RCT via multiple camera portals versus the limitations from the approach using an open technique $(41,56)$.

Success rates following arthroscopic repair of large/massive RCTs are encouraging. Denard et al. in their series of 126 repairs with a mean follow-up of 99 months showed $78 \%$ good to excellent outcomes. They noted that DR repair showed 4.9 times more likelihood of achieving good to excellent outcomes compared to SR repair but this was dependant on achieving acceptable tendon length (57). Iagulli et al. reported significant improvements in UCLA scores following both partial and complete arthroscopic large/massive RCT repairs at an average of 2 years followup. They concluded that there was no significant difference between partial and complete repairs in their cohort of 86 patients (58). Complete repair of massive RCTs have been shown to improve outcomes particularly with active external rotation as shown by Moser et al. (59).

\subsubsection{Tendon Transfers}

Even with recent advancements with regards to fixation methods for large/massive RCTs, there is an increased potential for failure, irreparability and the need for revision surgery. Tendon transfers for rotator cuff insufficiency is another option. Latissimus dorsi tendon transfer provides promising and reproducible results in cases with massive tendon retraction or in salvage situations (60). This involves transferring the insertion point of the tendon from the humerus onto the greater tuberosity (61). Systemic reviews by Longo et al. and Namdari et al. does suggest that latissimus dorsi transfer are an acceptable option in the setting of large, irreparable tears with overall improvements in outcome scores $(62,63)$. A ten year follow-up study by Gerber et al. while showing an overall benefit following latissimus dorsi tendon transfer, did suggest a guarded prognosis especially in patients with concomitant subscapularis tears, fatty infiltration of the teres minor muscle and large critical shoulder angles (64).

\subsubsection{Biological Augmentation}

Biological based strategies are a hot topic in contemporary orthopaedic research. These a broadly categorised 
to modalities to improve the repair site/tendon-to-bone healing environment and bridging techniques across large tears. Repair site augmentation options include gene therapy, stem cells, growth factors, transcription factors and platelet rich plasma (PRP) (65-74). Studies into these options are still on-going with most results based on animal-research models. Regarding PRP particular, while clinical trials have shown some short term benefits, 2 year healing rates of cuff repairs have not been statistically different than controls (73).

Bridging techniques with either biological (autograft, allograft and xenograft) and synthetic (extra-cellular matrices with scaffolds) provides an interesting option when considering patients with large/retracted RCTs. Synthetic scaffolds have shown good long-term functional and biocompatibility results as well as increasing the tensile load to failure at initial repair $(75,76)$. Promising results have also been shown using dermal tissue matrix xenograft in active patients with massive tears at 2 year follow-up (68). Still more research is required to ascertain the long term biocompatibility and outcomes following biological augmentation for large/massive RCTs.

\section{Conclusions}

Management of large/massive cuff tears associated with degenerative musculature remains a challenging prospect. The potential for inferior outcomes needs to be understood by both patient and surgeon. Surgical techniques such as stronger tendon-to-bone construct (double-row fixation), improved medial-to-lateral excursions and margin convergence may prove useful in improving outcomes when dealing with these difficult cuff pathologies. Salvage options like latissimus dorsi transfers do appear promising with acceptable long term results. More research into biological augments, scaffolds and grafts may prove to be future options in improving outcomes and possibly delaying/avoiding salvage procedures in dealing with large, degenerate rotator cuff tears.

\section{References}

1. Diercks RL, Ham SJ, Ros JM. [Results of anterior shoulder decompression surgery according to Neer for shoulder impingement syndrome; little effect on fitness for work]. Ned Tijdschr Geneeskd. 1998;142(22):1266-9. [PubMed: 9749299]

2. Lam F, Mok D. Open repair of massive rotator cuff tears in patients aged sixty-five years or over: is it worthwhile? J Shoulder Elbow Surg. 2004;13(5):517-21. doi: 10.1016/S1058274604000941. [PubMed: 15383807]

3. Sonnery-Cottet B, Edwards TB, Noel E, Walch G. Rotator cuff tears in middle-aged tennis players: results of surgical treatment. Am J Sports Med.2002;30(4):558-64. [PubMed:12130411]

4. Sperling JW, Cofield RH, Schleck C. Rotator cuff repair in patients fifty years of age and younger. J Bone Joint Surg Am. 2004;86A(10):2212-5. [PubMed: 15466730]

5. Tibone JE, Elrod B, Jobe FW, Kerlan RK, Carter VS, Shields CJ, et al. Surgical treatment of tears of the rotator cuff in athletes. J Bone Joint Surg Am. 1986;68(6):887-91. [PubMed:3733777]

6. Worland RL, Arredondo J, Angles F, Lopez-Jimenez F. Repair of massive rotator cuff tears in patients older than 70 years. JShoulder Elbow Surg. 1999;8(1):26-30. [PubMed: 10077792]

7. Liem D, Buschmann VE, Schmidt C, Gosheger G, Vogler T, Schulte
TL, et al. The prevalence of rotator cuff tears: is the contralateral shoulder at risk? Am J Sports Med. 2014;42(4):826-30. doi: 10.1177/0363546513519324. [PubMed: 24500916]

8. Hijioka A, Suzuki K, Nakamura T, Hojo T. Degenerative change and rotator cuff tears. An anatomical study in 160 shoulders of 80 cadavers. Arch Orthop Trauma Surg. 1993;112(2):61-4. [PubMed: 8457412]

9. Reilly P, Macleod I, Macfarlane R, Windley J, Emery RJ. Dead men and radiologists don't lie: a review of cadaveric and radiological studies of rotator cuff tear prevalence. Ann R Coll Surg Engl. 2006;88(2):116-21. doi: 10.1308/003588406X94968. [PubMed: 16551396]

10. Tashjian RZ. Epidemiology, natural history, and indications for treatment of rotator cuff tears. Clin Sports Med. 2012;31(4):589604. doi:10.1016/j.csm.2012.07.001. [PubMed: 23040548]

11. Moor BK, Wieser K, Slankamenac K, Gerber C, Bouaicha S. Relationship of individual scapular anatomy and degenerative rotator cuff tears. J Shoulder Elbow Surg. 2014;23(4):536-41. doi: 10.1016/j.jse.2013.11.008. [PubMed: 24480324]

12. Kannus P, Jozsa L. Histopathological changes preceding spontaneous rupture of a tendon. A controlled study of 891 patients. $J$ Bone Joint Surg Am. 1991;73(10):1507-25. [PubMed: 1748700]

13. Matthews TJ, Hand GC, Rees JL, Athanasou NA, Carr AJ. Pathology of the torn rotator cuff tendon. Reduction in potential for repair as tear size increases. J Bone Joint Surg Br. 2006;88(4):489-95. doi: 10.1302/0301-620X.88B4.16845. [PubMed:16567784]

14. Jones CK, Savoie F3. Arthroscopic repair of large and massive rotator cuff tears. Arthroscopy. 2003;19(6):564-71. [PubMed: 12861193]

15. Lenza M, Buchbinder R, Takwoingi Y, Johnston RV, Hanchard NC, Faloppa F. Magnetic resonance imaging, magnetic resonance arthrography and ultrasonography for assessing rotator cuff tears in people with shoulder pain for whom surgery is being considered. Cochrane Database Syst Rev. 2013;9 doi: 10.1002/14651858. CD009020.pub2. [PubMed: 24065456]

16. Toyoda H, Ito Y, Tomo H, Nakao Y, Koike T, Takaoka K. Evaluation of rotator cuff tears with magnetic resonance arthrography. Clin Orthop Relat Res. 2005;439:109-15. [PubMed: 16205148]

17. Dwyer T, Razmjou H, Henry P, Gosselin-Fournier S, Holtby R. Association between pre-operative magnetic resonance imaging and reparability of large and massive rotator cuff tears. Knee Surg Sports Traumatol Arthrosc. 2015;23(2):415-22. doi: 10.1007/s00167013-2745-z. [PubMed: 24170190]

18. Gerber C, Meyer DC, Frey E, von Rechenberg B, Hoppeler H, Frigg R, et al. Neer Award 2007: Reversion of structural muscle changes caused by chronic rotator cuff tears using continuous musculotendinous traction. An experimental study in sheep. I Shoulder Elbow Surg. 2009;18(2):163-71. doi: 10.1016/j.jse.2008.09.003. [PubMed: 19095462]

19. Goutallier D, Bernageau JPD. Assessment of the trophicity of the muscles of the ruptured rotator cuff by CT scan. In:Morrey BFHR, editor. Surgery of the Shoulder. St. Louis: Mosby; 1990. pp.11-3.

20. Fuchs B, Weishaupt D, Zanetti M, Hodler J, Gerber C. Fatty degeneration of the muscles of the rotator cuff: assessment by computed tomography versus magnetic resonance imaging. J Shoulder Elbow Surg. 1999;8(6):599-605. [PubMed:10633896]

21. Thomazeau H, Rolland Y, Lucas C, Duval JM, Langlais F. Atrophy of the supraspinatus belly. Assessment by MRI in 55 patients with rotator cuff pathology. Acta Orthop Scand. 1996;67(3):264-8. [PubMed: 8686465]

22. Zanetti M, Gerber C, Hodler J. Quantitative assessment of the muscles of the rotator cuff with magnetic resonance imaging. Invest Radiol.1998;33(3):163-70. [PubMed: 9525755]

23. Goutallier D, Postel JM, Bernageau J, Lavau L, Voisin MC. Fatty infiltration of disrupted rotator cuff muscles. Rev Rhum Engl Ed. 1995;62(6):415-22. [PubMed: 7552205]

24. Goutallier D, Postel JM, Bernageau J, Lavau L, Voisin MC. Fatty muscle degeneration in cuff ruptures. Pre- and postoperative evaluation by CT scan. Clin Orthop Relat Res. 1994;(304):78-83. [PubMed: 8020238]

25. Melis B, DeFranco MJ, Chuinard C, Walch G . Natural history of fatty infiltration and atrophy of the supraspinatus muscle in rotator cuff tears. Clin Orthop Relat Res . 2010 ;468(6):1498-505. 


\section{[PubMed: 20094853]}

26. Nakagaki K, Ozaki J, Tomita Y, Tamai S. Alterations in the supraspinatus muscle belly with rotator cuff tearing: Evaluation with magnetic resonance imaging. J Shoulder Elbow Surg. 1994;3(2):8893. doi: 10.1016/S1058-2746(09)80115-8. [PubMed: 22959647]

27. Jost B, Zumstein M, Pfirrmann CW, Gerber C. Long-term outcome after structural failure of rotator cuff repairs. J Bone Joint Surg Am. 2006;88(3):472-9. doi:10.2106/JBJS.E.00003. [PubMed:16510810]

28. Gerber C, Fuchs B, Hodler J. The results of repair of massive tears of the rotator cuff. J Bone Joint Surg Am. 2000;82(4):505-15. [PubMed: 10761941]

29. Warner JJ, Higgins L, Parsons I, Dowdy P. Diagnosis and treatment of anterosuperior rotator cuff tears. J Shoulder Elbow Surg. 2001;10(1):37-46. doi: 10.1067/mse.2001.112022. [PubMed: 11182734]

30. Thomazeau H, Boukobza E, Morcet N, Chaperon J, Langlais F. Prediction of rotator cuff repair results by magnetic resonance imaging. Clin Orthop Relat Res. 1997;(344):275-83. [PubMed: 9372778]

31. Gladstone JN, Bishop JY, Lo IK, Flatow EL. Fatty infiltration and atrophy of the rotator cuff do not improve after rotator cuff repair and correlate with poor functional outcome. Am J Sports Med. 2007;35(5):719-28. doi: 10.1177/0363546506297539. [PubMed: 17337727]

32. Goutallier D, Postel JM, Gleyze P, Leguilloux P, Van Driessche S. Influence of cuff muscle fatty degeneration on anatomic and functional outcomes after simple suture of full-thickness tears. J Shoulder Elbow Surg. 2003;12(6):550-4. doi: 10.1016| S1058274603002118. [PubMed:14671517]

33. Ellman H, Kay SP, Wirth M. Arthroscopic treatment of full-thickness rotator cuff tears: 2- to 7-year follow-up study. Arthroscopy. 1993;9(2):195-200. [PubMed: 8461081]

34. Scheibel M, Lichtenberg S, Habermeyer P. Reversed arthroscopic subacromial decompression for massive rotator cuff tears. J Shoulder Elbow Surg. 2004;13(3):272-8. doi: 10.1016| S1058274604000242. [PubMed: 15111896 ]

35. Levy HJ, Gardner RD, Lemak LJ. Arthroscopic subacromial decompression in the treatment of full-thickness rotator cuff tears. Arthroscopy. 1991;7(1):8-13. [PubMed: 2009126]

36. Zvijac JE, Levy HJ, Lemak LJ. Arthroscopic subacromial decompression in the treatment of full thickness rotator cuff tears: a 3- to 6-year follow-up. Arthroscopy. 1994;10(5):518-23. [PubMed: 7999159]

37. Itoi E, Tabata S. Conservative treatment of rotator cuff tears. Clin Orthop Relat Res. 1992;(275):165-73. [PubMed:1735208]

38. Murray TJ, Lajtai G, Mileski RM, Snyder SJ. Arthroscopic repair of medium to large full-thickness rotator cuff tears: outcome at 2- to 6-year follow-up. J Shoulder Elbow Surg. 2002;11(1):19-24. doi: 10.1067/mse.2002.120142. [PubMed: 11845144]

39. Warner JJ. Rotator cuff disease. An arthroscopic view. Orthop Clin North Am. 1997;28(2):251-65. [PubMed: 9113720]

40. Gerber C, Schneeberger AG, Beck M, Schlegel U. Mechanical strength of repairs of the rotator cuff. J Bone Joint Surg Br. 1994;76(3):371-80. [PubMed: 8175836]

41. Kim DH, Elattrache NS, Tibone JE, Jun BJ, DeLaMora SN, Kvitne RS, et al. Biomechanical comparison of a single-row versus doublerow suture anchor technique for rotator cuff repair. Am J Sports Med. 2006;34(3):407-14. doi:10.1177/0363546505281238. [PubMed: $16282581]$

42. Ma CB, Comerford L, Wilson J, Puttlitz CM. Biomechanical evaluation of arthroscopic rotator cuff repairs: double-row compared with single-row fixation. J Bone Joint Surg Am. 2006;88(2):403-10. doi:10.2106/JBJS.D.02887. [PubMed:16452754]

43. Meier SW, Meier JD. The effect of double-row fixation on initial repair strength in rotator cuff repair: a biomechanical study. Arthroscopy. 2006;22(11):1168-73. doi: 10.1016/j.arthro.2006.07.004. [PubMed:17084292]

44. Burks RT, Crim J, Brown N, Fink B, Greis PE. A prospective randomized clinical trial comparing arthroscopic single- and double-row rotator cuff repair: magnetic resonance imaging and early clinical evaluation. Am J Sports Med. 2009;37(4):674-82. doi: 10.1177/0363546508328115. [PubMed: 19204365]

45. Franceschi F, Ruzzini L, Longo UG, Martina FM, Zobel BB, Maffulli
$\mathrm{N}$, et al. Equivalent clinical results of arthroscopic single-row and double-row suture anchor repair for rotator cuff tears: a randomized controlled trial. Am J Sports Med. 2007;35(8):1254-60. doi:10.1177/0363546507302218. [PubMed:17554104]

46. Grasso A, Milano G, Salvatore M, Falcone G, Deriu L, Fabbriciani C Single-row versus double-row arthroscopic rotator cuff repair: a prospective randomized clinical study. Arthroscopy. 2009;25(1):412. doi:10.1016/j.arthro.2008.09.018. [PubMed:19111212]

47. Park JY, Lhee SH, Choi JH, Park HK, Yu JW, Seo JB. Comparison of the clinical outcomes of single- and double-row repairs in rotator cuff tears. Am J Sports Med. 2008;36(7):1310-6. doi: 10.1177/0363546508315039. [PubMed: 18413680 ]

48. Burkhart SS. A stepwise approach to arthroscopic rotator cuff repair based on biomechanical principles. Arthroscopy. 2000;16(1):82-90. [PubMed:10627351]

49. Burkhart SS, Athanasiou KA, Wirth MA. Margin convergence: a method of reducing strain in massive rotator cuff tears. Arthroscopy. 1996;12(3):335-8. [PubMed: 8783829]

50. LoIK, Burkhart SS. Arthroscopic repair of massive, contracted,immobile rotator cuff tears using single and double interval slides: technique and preliminary results. Arthroscopy. 2004;20(1):22-33. doi:10.1016/j.arthro.2003.11.013. [PubMed:14716275]

51. Tauro JC. Arthroscopic repair of large rotator cuff tears using the interval slide technique. Arthroscopy. 2004;20(1):13-21. doi: 10.1016/j.arthro.2003.10.013. [PubMed:14716274]

52. Kim SJ, Kim SH, Lee SK, Seo JW, Chun YM. Arthroscopic repair of massive contracted rotator cuff tears: aggressive release with anterior and posterior interval slides do not improve cuff healing and integrity. J Bone Joint Surg Am. 2013;95(16):1482-8. doi:10.2106| JBJS.L.01193. [PubMed: 23965698]

53. Kim SH, Ha KI, Park JH, Kang JS, Oh SK, Oh I. Arthroscopic versus mini-open salvage repair of the rotator cuff tear: outcome analysis at 2 to 6 years' follow-up. Arthroscopy. 2003;19(7):746-54. [PubMed: 12966383]

54. Morse K, Davis AD, Afra R, Kaye EK, Schepsis A, Voloshin I. Arthroscopic versus mini-open rotator cuff repair: a comprehensive review and meta-analysis. Am J Sports Med. 2008;36(9):18248. doi:10.1177/0363546508322903. [PubMed:18753683]

55. Shan L, Fu D, Chen K, Cai Z, Li G. All-arthroscopic versus miniopen repair of small to large sized rotator cuff tears: a meta-analysis of clinical outcomes. PLoS One. 2014;9(4):e94421. doi: 10.1371/ journal.pone.0 094421. [PubMed: 24728326]

56. Burkhart SS, Danaceau SM, Pearce CJ. Arthroscopic rotator cuff repair: Analysis of results by tear size and by repair techniquemargin convergence versus direct tendon-to-bone repair. Arthroscopy. 2001;17(9):905-12. doi: 10.1053/jars.2001.26821. [PubMed:11694920]

57. Denard PJ, Jiwani AZ, Ladermann A, Burkhart SS. Long-term outcome of arthroscopic massive rotator cuff repair: the importance of double-row fixation. Arthroscopy. 2012;28(7):909-15. doi: 10.1016/j.arthro.2011.12.007. [PubMed: 22365267]

58. Iagulli ND, Field LD, Hobgood ER, Ramsey JR, Savoie F3. Comparison of partial versus complete arthroscopic repair of massive rotator cuff tears. Am J Sports Med. 2012;40(5):1022-6. doi: 10.1177/0363546512438763. [PubMed: 22415210]

59. Moser M, Jablonski MV, Horodyski M, Wright TW. Functional outcome of surgically treated massive rotator cuff tears: a comparison of complete repair, partial repair, and debridement. Orthopedics. 2007;30(6):479-82. [PubMed:17598493]

60. Qadir R, Romine L, Yao DC, Duncan SF. Latissimus dorsi tendon transfer for massive, irreparable posterosuperior rotator cuff tears: surgical technique. Tech Hand Up Extrem Surg. 2014;18(3):125-30. doi: 10.1097/BTH.0000000000000050. [PubMed: 24854152]

61. Tauber M, Moursy M, Forstner R, Koller H, Resch H. Latissimus dorsi tendon transfer for irreparable rotator cuff tears: a modified technique to improve tendon transfer integrity: surgical technique. J Bone Joint Surg Am. 2010;92 Suppl 1 Pt 2:226-39. doi: 10.2106/JBJS.J.00224. [PubMed: 20844178]

62. Longo UG, Franceschetti E, Petrillo S, Maffulli N, Denaro V. Latissimus dorsi tendon transfer for massive irreparable rotator cuff tears: a systematic review. Sports Med Arthrosc. 2011;19(4):428-37. 
doi:10.1097/JSA.0b013e3182390639. [PubMed: 22089293]

63. Namdari S, Voleti P, Baldwin K, Glaser D, Huffman GR. Latissimus dorsi tendon transfer for irreparable rotator cuff tears: a systematic review. J Bone Joint Surg Am. 2012;94(10):891-8. doi: 10.2106/ JBJS.K.00841. [PubMed: 22617916]

64. Gerber C, Rahm SA, Catanzaro S, Farshad M, Moor BK. Latissimus dorsi tendon transfer for treatment of irreparable posterosuperior rotator cuff tears: long-term results at a minimum follow-up of ten years. J Bone Joint Surg Am. 2013;95(21):1920-6. doi: 10.2106| JBJS.M.00122. [PubMed: 24196461]

65. Gamradt SC, Lieberman JR. Genetic modification of stem cells to enhance bone repair. Ann Biomed Eng. 2004;32(1):136-47. [PubMed:14964729]

66. Gulotta LV, Kovacevic D, Ehteshami JR, Dagher E, Packer JD, Rodeo SA.Application of bone marrow-derived mesenchymal stem cells in a rotator cuff repair model. Am J Sports Med. 2009;37(11):212633. doi: 10.1177/0363546509339582. [PubMed:19684297]

67. Gulotta LV, Kovacevic D, Montgomery S, Ehteshami JR, Packer JD, Rodeo SA. Stem cells genetically modified with the developmental gene MT1-MMP improve regeneration of the supraspinatus tendon-to-bone insertion site. Am J Sports Med. 2010;38(7):142937. doi: $10.1177 / 0363546510361235$. [PubMed: 20400753 ]

68. Gupta AK, Hug K, Boggess B, Gavigan M, Toth AP. Massive or 2-tendon rotator cuff tears in active patients with minimal glenohumeral arthritis: clinical and radiographic outcomes of reconstruction using dermal tissue matrix xenograft. Am J Sports Med. 2013;41(4):872-9. doi: 10.1177/0363546512475204. [PubMed: 23423315]

69. Ide J, Kikukawa K, Hirose J, Iyama K, Sakamoto H, Mizuta H. The effects of fibroblast growth factor-2 on rotator cuff reconstruction with acellular dermal matrix grafts. Arthroscopy. 2009;25(6):608-
16. doi:10.1016/j.arthro.2008.11.011. [PubMed:19501290]

70. Kobayashi M, Itoi E, Minagawa H, Miyakoshi N, Takahashi S, Tuoheti Y, et al. Expression of growth factors in the early phase of supraspinatus tendon healing in rabbits. J Shoulder Elbow Surg. 2006;15(3):371-7. doi: 10.1016/j.jse.2005.09.003. [PubMed: 16679241]

71. Mazzocca AD, McCarthy MB, Chowaniec DM, Cote MP, Arciero RA, Drissi H. Rapid isolation of human stem cells (connective tissue progenitor cells) from the proximal humerus during arthroscopic rotator cuff surgery. Am J Sports Med. 2010;38(7):143847. doi:10.1177/0363546509360924. [PubMed:20375368]

72. Musgrave DS, Fu FH, Huard J. Gene therapy and tissue engineering in orthopaedic surgery. J Am Acad Orthop Surg. 2002;10(1):615. [PubMed:11809046]

73. Randelli P, Arrigoni P, Ragone V, Aliprandi A, Cabitza P. Platelet rich plasma in arthroscopic rotator cuff repair: a prospective RCT study, 2-year follow-up. J Shoulder Elbow Surg. 2011;20(4):51828. doi:10.1016/j.jse.2011.02.008. [PubMed:21570659]

74. Wurgler-Hauri CC, Dourte LM, Baradet TC, Williams GR, Soslowsky LJ. Temporal expression of 8 growth factors in tendonto-bone healing in a rat supraspinatus model. J Shoulder Elbow Surg. 2007;16(5 Suppl):S198-203. doi: 10.1016/j.jse.2007.04.003. [PubMed:17903711]

75. Cole BJ, Gomoll AH, Yanke A, Pylawka T, Lewis P, Macgillivray JD, et al. Biocompatibility of a polymer patch for rotator cuff repair. Knee Surg Sports Traumatol Arthrosc. 2007;15(5):632-7. doi:10.1007| s00167-006-0187-6. [PubMed:16964514]

76. Santoni BG, McGilvray KC, Lyons AS, Bansal M, Turner AS, Macgillivray JD, et al. Biomechanical analysis of an ovine rotator cuff repair via porous patch augmentation in a chronic rupture model. Am J Sports Med. 2010;38(4):679-86. doi: 10.1177/0363546510366866. [PubMed: 20357402] 